\title{
EFL Learners' Reading Strategy Use in Relation to Reading Anxiety
}

\author{
Hsin-Yi Lien \\ Ming Chuan University, Taiwan
}

\begin{abstract}
The study investigated EFL learners' reading strategies use in relation to reading anxiety and gender after their participation in extensive reading as a supplemental course requirement. One hundred and eight EFL college freshmen completed a questionnaire, a survey of Foreign Language Reading Anxiety Scale (FLRAS), and a modified Survey of Reading Strategies (SORS) after eighteen weeks of participation in extensive reading. The results indicate a negative correlation between reading anxiety and reading strategies. It was also found that EFL learners with low anxiety levels tended to use general reading strategies such as guessing, while EFL learners with high anxiety levels employed basic support mechanisms, such as translation, to help themselves understand texts. Some reading strategies were more used by high-anxiety level readers than low-anxiety level readers. Additionally, females tended to be slightly more anxious than males in reading.
\end{abstract}

Language anxiety, a complex psychological construct, is regarded as an affective variable in the language learning process. Research on language anxiety has examined the possible relationship between anxiety and performance, and its interference in language competence (Horwitz, Horwitz, \& Cope, 1986; Maclntyre \& Gardner, 1989; Sellers, 2000). The majority of studies have centered on the influence of language anxiety on listening or speaking in language classroom (Horwitz et al., 1986; Phillips, 1992; Price, 1991; Young, 1991). However, anxiety also can be a crucial filter for foreign language (FL) learners as they attempt to comprehend reading or listening passages. The literature on foreign language reading suggests that affective variables such as anxiety could be contributing factors in reading performance (Mohd. Zin \& Rafik-Galea, 2010; Saito, Horwitz, \& Garza, 1999; Sellers, 2000). In a preliminary study, Saito et al. (1999) indicated that foreign language reading anxiety is distinct from general foreign language anxiety and concluded that learners' levels of reading anxiety were correlated with their reading performance.

Another important variable associated with reading performance is EFL learners' use of reading strategies. The relationship between reading strategy use and reading comprehension has been of interest to researchers, since the efficient use of reading strategies benefits learners' reading comprehension to some degree (Al-Nujaidi, 2003; Brantmeier, 2000; Lee, 2007; Wu, 2005). Reading strategies, as Brantmeier (2002) indicated, are "the comprehension processes that readers use in order to make sense of what they read" (p. 1); they are characterized as

Language Education in Asia, 2011, 2(2), 199-212. http://dx.doi.org/10.5746/LEiA/11/V2/I2/A03/Lien 
approaches, actions, and procedures used to improve reading comprehension. Since reading anxiety and reading strategies are two important influences on reading comprehension, the present study aims to investigate EFL learners' use of reading strategies and gender differences in relation to their reading anxiety levels.

\section{Literature Review}

\section{Foreign Language Reading Anxiety}

Horwitz et al. (1986) defined foreign language anxiety as "a distinct complex of selfperceptions, beliefs, feelings, and behaviors related to classroom language learning arising from the uniqueness of the language learning process" (p. 128). Foreign language anxiety negatively affects learner confidence and self-esteem (Horwitz et al., 1986). More anxious learners may not recall material learned before (Horwitz et al., 1986; Sellers, 2000) and compared to learners who are less anxious, may be less active in class (Ely, 1986; Horwitz et al., 1986).

Researchers of language anxiety have investigated the possible relationship between reading anxiety and language proficiency to identify whether reading anxiety might predict language performance and reading comprehension (Saito, et al., 1999; Sas, 2002). In other words, learners with higher anxiety levels might comprehend reading texts more poorly.

A study by lpek (2004) revealed that reading anxiety levels varied in conjunction with language proficiency. Learners at the advanced level seem to be less anxious compared with beginner and intermediate level students (Elkhafaifi, 2005; Liu, 2006)

Foreign language scholars have also recognized that anxiety in foreign language learning can facilitate as well as debilitate. An appropriate level of anxiety leads to better learner achievements because learners do not want to harm their self-esteem. However, the majority of studies have shown that foreign language anxiety indeed has a negative influence on the learning process and performance (Horwitz et al., 1986; Maclntyre \& Gardner, 1989; Sellers, 2000; Young, 1991).

\section{Reading Strategies}

Learners who are incapable of effectively comprehending reading texts may experience great frustration and may not have motivation for further learning. Thus, researchers study the use of reading strategies to reduce reading anxiety and to enhance reading performance.

Reading strategies are techniques or conscious actions taken to improve understanding and solve difficulties encountered in reading. Reading strategies include reading aloud, paraphrasing, guessing, re-reading the text, visualizing the information, asking oneself questions, translating, and using a dictionary. The successful use of reading strategies benefits learners' reading comprehension (Huang, Chern, \& Lin, 2009). Additionally, several studies have shown reading strategy use is also positively correlated with reading comprehension (AlNujaidi, 2003; Darabie, 2000; Song, 1999).

Moreover, diverse variables related to EFL learners' reading strategy use, such as gender, proficiency levels, personality, and language context, are of interest to researchers. Campbell (1999) explored language anxiety in relation to gender in the four skills and found that from two weeks before the study treatment to two weeks after, the percentage of women with reading anxiety fell by $7 \%$, while the percentage of men experiencing anxiety rose around $9 \%$. Mangubhai (1990) examined reading strategy use in relation to English proficiency and found 
learners at a higher proficiency level tended to apply background knowledge to understand the text, but learners at a lower proficiency level seldom used any effective reading strategies to solve the difficulties encountered. Studies conducted by Al-Nujaidi (2003) and Wu (2005) showed that learners with higher reading proficiency levels employed reading strategies more frequently than those with lower proficiency levels.

Another affective variable, reading anxiety, has also been researched in relation to reading strategies. Oh (1990) indicated EFL readers use different reading strategies under the influence of anxiety. Sellers (2000) also found that learners with a high anxiety level use translation strategies directly while low-anxiety learners read the text more holistically and use more reading strategies.

Since a limited number of studies have investigated EFL learners at various levels of FL reading anxiety with respect to reading strategies and gender, the study proposes the following research questions:

1. Does EFL learners' reading anxiety vary in relation to reading strategies?

2. Do FL reading anxiety levels and reading strategies vary with respect to gender?

\section{Research Method}

\section{Participants}

One hundred and eight EFL freshmen (22 males and 86 females) participated in the study for eighteen weeks. They were enrolled in the Applied English Department as English majors at a university in northern Taiwan. The majority of the participants had studied English for at least nine years, and their English proficiency level was at the intermediate level. The participants were taking basic courses, such as reading, writing, and grammar. In the reading course, intensive reading activities to improve reading comprehension, reading strategies, and reading speed were employed in class. In addition, extensive reading was required; students had to read as many books in English as possible outside the classroom. They chose from graded readers, authentic fiction, or other types of authentic materials, submitted a written report for each book finished to provide evidence of reading and reading comprehension, and kept a reading log.

\section{Instruments}

The present study employed three instruments: a questionnaire, the Foreign Language Reading Anxiety Scale (FLRAS) and the Survey of Reading Strategies (SORS). The questionnaire was administered to investigate the background and reading habits of the participants. The second instrument, the 20-item FLRAS, designed by Saito et al. (1999), was used to investigate the participants' reading anxiety (see Appendix A). SORS, designed by Sheorey and Mokhtari (2001), was modified to investigate the participants' extensive reading strategies use after participating in the extensive reading program as a supplemental requirement in the reading class and was additionally adapted to measure metacognitive reading strategies (see Appendix B). It includes three subcategories: Global Reading Strategies (GLOB), Problem Solving Strategies (PROB), and Support Strategies (SUP). Global Reading Strategies allow readers to intentionally monitor or manage their reading. Problem Solving Strategies help readers to directly solve reading difficulties. Support Strategies are basic mechanisms to enhance reading comprehension. 
The FLRAS items are rated by a five-point Likert scale, ranging from five points (strongly agree) to one point (strongly disagree), except for the scoring of positive items (i.e., Items 12, 13, 14, and 18), rated from one point (strongly agree) to five points (strongly disagree). The theoretical range of the total score is 20 to 100 . High scores on FLRAS indicate a high reading anxiety level. Additionally, the 30 -item SORS has a five-point Likert scale, ranging from one point (I never or almost never do this) to five points ( $/$ always or almost always do this). The range of scores is from 30 to 150 . The higher scores refer to the more frequent use of reading strategies.

In the present study, to eliminate the possible language barrier, the Chinese versions of FLRAS and SORS were employed and the internal reliability with an internal consistency coefficient was .798 and .876 (Cronbach's alpha, $N=108$ ), respectively.

\section{Procedure}

The participants were asked to complete the questionnaire, FLRAS, and SORS after the eighteen-week reading course.

\section{Results}

\section{Research Question 1: Does EFL learners' reading anxiety vary in relation to reading strategies?}

The FLRAS scores were significantly and negatively correlated with the SORS scores, $r(106)=-$ $.268, p<.01$. The FLRAS scores were also correlated with the SORS subcategories, Global Reading Strategies $[r(106)=-.401, p<.01]$ and Problem Solving Strategies $[r(106)=-.238, p<$ $.01]$, respectively, but were weakly correlated with Support Strategies $[r(106)=.020, p<.01]$.

The descriptive statistics of FLRAS and SORS showed that the mean score of the FLRAS was $60.57(S D=7.49)$ while the mean score of SORS was $99.33(S D=13.60)$. Among the three SORS subcategories, the mean of every item in Problem Solving Strategies was slightly higher than the mean of the other two subcategories. The participants used Problem Solving Strategies more frequently and Support Strategies the least frequently.

Table 1 displayed three strategies used most and least frequently by the participants. The results showed that the participants used fundamental reading strategies such as trying to get back on track when losing concentration and using tables, figures, pictures and context clues to help them to understand reading texts. However, they seldom used more advanced reading strategies, such as critically analyzing and evaluating information, asking themselves questions, or taking notes.

Table 1

Descriptive Statistics of Most and Least Used Reading Strategies

\begin{tabular}{lllccc}
\hline & Category & Strategy & Min & Max & Mean \\
\hline Most & PROB2 & Try to get back on track when losing concentration & 1 & 5 & 3.94 \\
& GLOB7 & Use tables, figures, and pictures & 1 & 5 & 3.92 \\
& GLOB8 & Use context clues & 1 & 5 & 3.85 \\
\hline \multirow{2}{*}{ Least } & GLOB10 & Critically analyze and evaluate the information & 1 & 4 & 2.29 \\
& SUP7 & Ask myself questions & 1 & 5 & 2.35 \\
& SUP1 & Take notes & 1 & 5 & 2.46 \\
\hline
\end{tabular}

To further compare the participants' differences in using reading strategies, the participants were divided into three anxiety groups (high, medium, and low) according to standard 
deviation. The participants with a mean above one standard deviation comprised the highanxiety group; those with a mean below one standard deviation were in the low-anxiety group. The remaining participants were placed into the medium-anxiety group. Seventeen participants belonged to the low-anxiety group, 70 were in the medium-anxiety group, and 21 were in the high-anxiety group. Table 2 shows that the high-anxiety group employed Support Strategies more often, the medium-anxiety group used Problem Solving Strategies more often, and the low-anxiety group adopted Global Reading Strategies more often. The participants in the low-anxiety group tended to use general strategies to intentionally monitor or manage their reading, while the high-anxiety group seemed to employ reading techniques such as taking notes, reading aloud, and circling information.

Table 2

Reading Strategy Use by Category for Different Anxiety Levels

\begin{tabular}{lllcrr}
\hline Anxiety Group & Category & N & Min & Max & \multicolumn{1}{c}{ Mean } \\
\hline Low & SORS & 17 & 75 & 133 & 100.58 \\
& GLOB & 17 & 32 & 61 & 45.00 \\
& SUP & 17 & 17 & 36 & 26.82 \\
\multirow{2}{*}{ Medium } & PROB & 17 & 21 & 36 & 28.76 \\
\hline & SORS & 70 & 71 & 136 & 100.48 \\
& GLOB & 70 & 29 & 57 & 43.40 \\
& SUP & 70 & 17 & 43 & 27.70 \\
\hline \multirow{7}{*}{ High } & PROB & 70 & 20 & 38 & 29.38 \\
& SORS & 21 & 73 & 115 & 94.47 \\
& GLOB & 21 & 30 & 51 & 39.33 \\
& SUP & 21 & 21 & 36 & 28.23 \\
& PROB & 21 & 17 & 37 & 26.90 \\
\hline
\end{tabular}

The reading strategies used most and least by the three anxiety groups are displayed in Table 3 . The low-anxiety group used context clues (GLOB8) the most and took notes (SUP1) the least, while the medium-anxiety group tried to get back on track when losing concentration (PROB2) the most and critically analyzed and evaluated the information (GLOB10) the least. On the other hand, the high-anxiety group translated from English into their native language (SUP8) the most and critically analyzed and evaluated the information (GLOB10) the least. It is surprising to find that the three anxiety groups all seldom took notes (SUP1), asked themselves questions (SUP7), or critically analyzed and evaluated information (GLOB10). The low-anxiety and medium-anxiety groups both used context clues (GLOB8) more often and the high-anxiety group used the translation strategy (SUP8) the most. 
Research

Table 3

Reading Strategies Used Most and Least by Anxiety Level

\begin{tabular}{lllrr}
\hline $\begin{array}{l}\text { Anxiety } \\
\text { Group }\end{array}$ & Category & \multicolumn{1}{c}{ Most and Least Used Strategies } & Mean & SD \\
\hline Low & GLOB8 & Use context clues & 4.05 & .55 \\
& GLOB2 & Use background knowledge & 3.94 & .74 \\
& PROB8 & Guess the meaning of unknown word & 3.94 & .74 \\
\cline { 2 - 5 } & SUP1 & Take notes & 2.29 & 1.21 \\
& SUP7 & Ask myself questions & 2.41 & 1.12 \\
& GLOB4 & Think about if the content fits my reading purpose & 2.70 & .91 \\
& GLOB10 & Critically analyze and evaluate the information & 2.70 & 1.04 \\
\hline Medium & PROB2 & Try to get back on track when losing concentration & 4.01 & .80 \\
& GLOB7 & Use tables, figures, and pictures & 4.00 & .79 \\
& GLOB8 & Use context clues & 3.91 & .86 \\
\cline { 2 - 5 } & GLOB10 & Critically analyze and evaluate the information & 2.25 & .86 \\
& SUP7 & Ask myself questions & 2.35 & .99 \\
& SUP1 & Take notes & 2.48 & .94 \\
\hline High & SUP8 & Translate from English into my native language & 3.76 & .88 \\
& PROB2 & Try to get back on track when losing concentration & 3.76 & .94 \\
& GLOB7 & Use tables, figures, and pictures & 3.76 & 1.04 \\
\hline & GLOB10 & Critically analyze and evaluate the information & 2.09 & .83 \\
& SUP7 & Ask myself questions & 2.28 & 1.00 \\
& SUP1 & Take notes & 2.52 & 1.12 \\
\hline
\end{tabular}

\section{Research Question 2: Do FL reading anxiety levels and reading strategies vary with respect to gender?}

An independent-samples t-test was conducted to compare the FLRAS and SORS scores of males and females. The results showed there was no significant difference for males $(M=$ $59.54, S D=7.53)$ and females $[M=60.83, S D=7.51 ; t(106)=-.719, p=.474]$ in the FLRAS scores. There was also no significant difference for males $(M=59.54, S D=7.53)$ and females $[M$ $=102.68, S D=13.64 ; t(106)=-.719, p=.474]$ in the SORS scores. However, males seemed to be less anxious than females and tended to use more reading strategies than females.

Twenty-three percent of the males belonged to the low-anxiety group while only $14 \%$ of the females did. The percentages of males and females in the high-anxiety group were close, at $18 \%$ and $20 \%$, respectively. As Table 4 shows, males tended to use Global Reading Strategies more frequently to monitor or manage their reading; females tended to use Problem Solving Strategies the most. Both males and females used tables, figures, and pictures to help their understanding more often, but seldom used the strategies of asking themselves questions, taking notes, and critically analyzing and evaluating information. 
Table 4

Reading Strategies Used Most and Least by Gender

\begin{tabular}{cllcccc}
\hline Sex & Category & \multicolumn{1}{c}{ Strategy } & $N$ & Min & Max & Mean \\
\hline Male & GLOB7 & Use tables, figures, and pictures & 22 & 3 & 5 & 4.18 \\
& GLOB2 & Use background knowledge & 22 & 2 & 5 & 4.00 \\
& GLOB8 & Use context clues & 22 & 2 & 5 & 4.00 \\
\cline { 2 - 8 } & SUP7 & Ask myself questions & 22 & 1 & 4 & 2.40 \\
& SUP1 & Take notes & 22 & 1 & 5 & 2.54 \\
& GLOB10 & Critically analyze and evaluate & 22 & 1 & 4 & 2.63 \\
& information & Try to get back on track when losing & 86 & 1 & 5 & 4.01 \\
\hline Female & PROB2 & concentration & 86 & 1 & 5 & 3.82 \\
& SUP4 & Use a dictionary & 86 & 1 & 5 & 3.86 \\
\hline & GLOB7 & Use tables, figures, and pictures & 86 & 1 & 4 & 2.20 \\
& GLOB10 & Critically analyze and evaluate & 86 & 1 & 5 & 2.33 \\
& information & 86 & 1 & 5 & 2.44 \\
\hline
\end{tabular}

\section{Discussion}

Language anxiety is regarded as a key factor in reading comprehension. The present study analyzes EFL learners' reading strategy use in relation to reading anxiety level and gender differences after their participation in extensive reading as a supplementary requirement in reading class. The results showed that the FLRAS scores were negatively correlated with the SORS scores; the participants with more reading anxiety used fewer reading strategies, as expected. Among the three subcategories of SORS, FLRAS was correlated with Global Reading Strategies and Problem Solving Strategies, respectively, but was weakly correlated with Support Strategies. This might suggest that less anxious readers use more Global Reading Strategies to intentionally monitor or manage their own reading than more anxious readers, and that most readers, anxious or not, still employ Support Strategies, basic support mechanisms to help them understand texts. Consequently, EFL teachers may need to pay more attention to training learners in Global Reading Strategies to enable learners to consciously monitor their own learning, with the aim of reducing their reading anxiety.

Comparing the mean score of $52.9(S D=9.4)$ of the American students in the Saito et al. (1999) study to the mean of $60.57(S D=7.49)$ of the Chinese EFL learners in the present study, the Chinese EFL learners seemed to have more reading anxiety. The results are similar to the findings in previous studies (Huang, 2001; Shi \& Liu, 2006). While analyzing the participants' use of the three reading strategy categories, it was found that the participants used Problem Solving Strategies the most frequently and Support Strategies the least frequently. This is similar to the conclusion drawn by Mo'nos (2005) and Wu (2005) that EFL college students majoring in English preferred to use Problem Solving Strategies the most and then Global Reading Strategies and Support Strategies the least. This might imply that EFL readers often encounter reading problems, so they are used to applying reading strategies such as trying to get back on track when losing concentration, but they seldom use reading strategies such as asking themselves questions or taking notes to support their reading. These two least-used reading strategies are important and helpful for readers to check their understanding of texts. Thus, EFL teachers might need to involve more Global Reading and Support Strategies in their reading classes to enable readers to reduce their reading anxiety and improve their reading performance and language proficiency. 
Reading strategy use by EFL learners at different anxiety levels is explored in this study. The results show that the high-anxiety group employed Support Strategies more often than the other groups, while the medium-anxiety group was more likely to use Problem Solving Strategies and the low-anxiety group more frequently used Global Reading Strategies. This might indicate that EFL learners in the low-anxiety group were confident and tended to use Global Reading Strategies such as guessing, referring to their background knowledge, or using tables or pictures to enable them to monitor or manage their reading. However, the participants in the highanxiety group seemed to employ Support Strategies such as translation, paraphrasing, or using a dictionary to help themselves understand the text. High-anxiety readers usually are less confident in enjoying the content of reading texts. While they are reading, they might just want to know the meanings of unfamiliar words and sentences. Ensuring understanding of the meanings of words or sentences will ease their anxiety and let them feel secure in reading. However, Global Reading Strategies might be more effective in reducing learners' anxiety, because readers will be more confident and relaxed when they are able to understand the whole picture a reading text represents by guessing or using their background knowledge. Therefore, teachers might introduce holistic reading strategies to build students' reading confidence.

Gender differences in reading anxiety and reading strategies are discussed in this study. Females seemed to be more anxious than males, and males used more reading strategies than females. The first finding is similar to the findings that females are more anxious than males (Abu-Rabia, 2004; Matsuda \& Gobel, 2004). The second finding, that males tended to use more reading strategies, is different from the findings in Green and Oxford's (1995) study. They pointed out that female foreign language learners seemed to use more learning strategies than male foreign language learners. However, their study was concerned with learning strategies and the finding in the present study is related to reading strategies, which are just a part of learning strategies. Additionally, in the present study, in regard to the use of the three subcategories of reading strategies, males employed Global Reading Strategies more frequently while females used Problem Solving Strategies more. Males may be more aware of their reading process and self-monitor their reading strategies, but females focus more on the strategies which help them to solve reading problems. The results also showed that both males and females often used tables, figures, and pictures to help their understanding, but seldom ask themselves questions, take notes, or critically analyze and evaluate information. These leastused strategies are considered to be significant and more advanced strategies that enable learners to examine and check their own reading. Thus, EFL reading instruction may try to focus more on self-evaluating reading strategies and give different reading strategy training based on learners' gender.

\section{Conclusion}

To conclude, foreign language reading anxiety indeed is negatively correlated with reading strategy use, and gender influences participants' reading anxiety and reading strategy use. In addition, the reading strategies employed by EFL learners at a high anxiety level were different from those at a low anxiety level, and females tended to be more anxious than males. The three anxiety groups seldom take notes, ask themselves questions, or critically analyze and evaluate information. Based on these findings, it seems essential for EFL teachers to teach more top-down reading strategies such as critically analyzing the texts, guessing the meaning of unknown words, using context clues, background knowledge, taking notes and asking oneself questions. These reading strategies will strengthen learners' confidence and provide them with a more holistic picture of each reading text. Although dictionary use or translation might help learners immediately solve reading problems, learners might rely on these strategies 
too much to benefit from or enjoy reading. Teachers should pay attention to reading strategies, which are important and essential for learners, and train their students to use these strategies more often.

From the findings of this study and examination of the different possibilities arising from various studies, room seems to exist for a thorough examination of reading strategies and reading anxiety. Further research needs to be conducted to evaluate the influence of reading strategies on foreign language reading self-efficacy and proficiency. In addition, many fundamental questions concerning foreign language reading anxiety, such as the source of foreign language reading anxiety and the relation between background variables, need further research.

\section{Author Note}

Hsin-Yi Lien, Department of Applied English, Ming Chuan University, Taiwan

Correspondence concerning this article should be addressed to Hsin-Yi Lien, Department of Applied English, Ming Chuan University, Taoyuan: 5 De Ming Road, Gui Shan District, Taoyuan County 333, Taiwan. E-mail: Maggielien61@hotmail.com 


\section{References}

Abu-Rabia, S. (2004). Teachers' role, learners' gender differences, and FL anxiety among seventh-grade students studying English as a FL. Educational Psychology, 24(5), 711 721. http://dx.doi.org/10.1080/0144341042000263006

Al-Nujaidi, A. H. (2003). The relationship between vocabulary size, reading strategies, and reading comprehension of EFL learners in Saudi Arabia (Unpublished doctoral dissertation). Oklahoma State University, Stillwater, OK, USA.

Brantmeier, C. (2000). The relationship between readers' gender, passage content, comprehension, and strategy use in reading Spanish as a second language (Unpublished doctoral dissertation). Indiana University, Bloomington, IN, USA.

Brantmeier, C. (2002). Second language reading strategy research at the secondary and university levels: Variations, disparities, and generalizability. The Reading Matrix, 2(3), 1-14. Available online at http://www.readingmatrix.com/articles/brantmeier/article.pdf

Campbell, C. M. (1999). Language anxiety in men and women: Dealing with gender difference in the language classroom. In D. J. Young (Ed.), Affect in foreign language and second language learning: A practical guide to creating a low anxiety classroom atmosphere (pp. 191-215). Boston, MA: McGraw Hill.

Darabie, M. Y. (2000). The relationship between college-level Jordanian students' metacognitive awareness strategies and their reading comprehension achievement in English as a foreign language (Unpublished doctoral dissertation). Ohio University, $\mathrm{OH}$, USA.

Elkhafaifi, H. (2005). Listening comprehension and anxiety in the Arabic language classroom. The Modern Language Journal, 89(2), 206-220. http://dx.doi.org/10.1111/j.15404781.2005.00275.x

Green, J., \& Oxford, R. (1995). A closer look at learning strategies, L2 proficiency, and gender. TESOL Quarterly, 29(2), 261-297. http://dx.doi.org/10.2307/3587625

Horwitz, E. K., Horwitz, M. B., \& Cope, J. A. (1986). Foreign language classroom anxiety. The Modern Language Journal, 70(2), 125-132. http://dx.doi.org/10.1111/j.15404781.1986.tb05256.x

Huang, H.-C., Chern, C.-L., \& Lin, C.-C. (2009). EFL learners' use of online reading strategies and comprehension of texts: An exploratory study. Computers \& Education, 52(1), 1326. http://dx.doi.org/10.1016/j.compedu.2008.06.003

Huang, H.-Y. (2001). Chinese university foreign language students' anxiety about reading in English (Unpublished doctoral dissertation). Washington State University, Pullman, WA, USA.

Ipek, H. (2004). Foreign language reading anxiety: Proficiency and gender. The International Journal of Learning, 16(8), 293-300.

Lee, K. R. (2007). Strategy awareness-raising for success: Reading strategy instruction in the EFL context (Unpublished doctoral dissertation). University of Maryland, College Park, MD, USA.

Liu, M. (2006). Anxiety in Chinese EFL students at different proficiency levels. System, 34(3), 301-316. http://dx.doi.org/10.1016/j.system.2006.04.004

Maclntyre, P. D., \& Gardner, R. C. (1989). Anxiety and second language learning: Toward a theoretical clarification. Language Learning, 39(2), 251-275.

http://dx.doi.org/10.1111/j.1467-1770.1989.tb00423.x

Mangubhai, F. (1990). Towards a taxonomy of strategies used by ESL readers of varying proficiencies while doing cloze exercises. Australian Journal of Reading, 13(2), 128139.

Matsuda, S. \& Gobel, P. (2004). Anxiety and predictors of performance in the foreign language classroom. System, 32(1), 21-36. http://dx.doi.org/10.1016/j.system.2003.08.002 
Mohd. Zin, Z., \& Rafik-Galea, S. (2010). Anxiety and academic reading performance among Malay ESL learners. Journal of Pan-Pacific Association of Applied Linguistics, 14(2), 41 58.

Mo'nos, K. (2005). A study of the English reading strategies of Hungarian university students with implications for reading instruction in an academic context. Malaysian Journal of ELT Research. Retrieved from http://www.melta.org.my/Doc/MonosK_Eng_reading_strategies.pdf

Oh, J. (1990). On the relationship between anxiety and reading in English as a foreign language among Korean university students in Korea. Dissertation Abstracts International, 52 (05), 1669.

Phillips, E. (1992). The effects of language anxiety on students' oral test performance and attitudes. The Modern Language Journal, 76(1), 14-26. http://dx.doi.org/10.1111/j.15404781.1992.tb02573.x

Price, M. L. (1991). The subjective experience of foreign language anxiety: Interviews with high anxiety students. In E. K. Horwitz \& D. J. Young (Eds.), Language anxiety: From theory and research to classroom applications (pp.101-108). Englewood Cliffs, NJ: PrenticeHall.

Saito, Y., Horwitz, E. K., \& Garza, T. J. (1999). Foreign language reading anxiety. The Modern Language Journal, 83(2), 202-218. http://dx.doi.org/10.1111/0026-7902.00016

Sas, M. M. (2002). Reading anxiety's effects on incidental vocabulary acquisition: Are culturally relevant texts exempt? (Unpublished doctoral dissertation). University of Nevada, Las Vegas, NV, USA.

Sellers, V. D. (2000). Anxiety and reading comprehension in Spanish as a foreign language. Foreign Language Annals, 33(5), 512-521. http://dx.doi.org/10.1111/j.19449720.2000.tb01995.x

Sheorey, R., \& Mokhtari, K. (2001). Differences in the metacognitive awareness of reading strategies among native and non-native readers. System, 29(4), 431-449. http://dx.doi.org/10.1016/S0346-251X(01)00039-2

Shi, Y. Z., \& Liu, Z. Q. (2006). Foreign language reading anxiety and its relationship to English achievement and gender. Journal of PLA University of Foreign Languages, 29, 59-65.

Song, M. J. (1999). Reading strategies and second language reading ability: The magnitude of the relationship. English Teaching, 54(3), 73-95.

Wu, C. P. (2005). An investigation of metacognitive reading strategies used by EFL Taiwanese college students to comprehend familiar versus unfamiliar Chinese and English texts (Unpublished doctoral dissertation). University of Idaho, ID, USA.

Young, D. J. (1991). Creating a low-anxiety classroom environment: What does language anxiety research suggest? The Modern Language Journal, 75, 426-437. http://dx.doi.org/10.1111/j.1540-4781.1991.tb05378.x 


\section{Appendix A \\ Foreign Language Reading Anxiety Scale}

(Saito, Horwitz, \& Garza, 1999)

Directions: Statements 1 through 20 refer to how you feel about reading English while you are doing extensive reading. For each statement, please indicate whether you (1) strongly agree, (2) agree, (3) neither agree nor disagree, (4) disagree, or (5) strongly disagree by marking the appropriate number on the line following each statement. Please give your first reaction to each statement and mark an answer for each statement.

$\mathrm{SA}=$ Strongly Agree $\mathrm{A}=$ Agree, $\mathrm{N}=$ Neutral, $\mathrm{D}=$ Disagree, $\mathrm{SD}=$ Strongly Disagree

\begin{tabular}{|c|c|c|c|c|c|c|}
\hline & & SA & A & $\mathrm{N}$ & D & SD \\
\hline 1 & $\begin{array}{l}\text { I get upset when I'm not sure whether I understand what I am } \\
\text { reading in English. }\end{array}$ & 1 & 2 & 3 & 4 & 5 \\
\hline 2 & $\begin{array}{l}\text { When reading English, I often understand the words but still } \\
\text { can't quite understand what the author is saying. }\end{array}$ & 1 & 2 & 3 & 4 & 5 \\
\hline 3 & $\begin{array}{l}\text { When I'm reading English, I get so confused I can't remember } \\
\text { what I'm reading }\end{array}$ & 1 & 2 & 3 & 4 & 5 \\
\hline 4 & $\begin{array}{l}\text { I feel intimidated whenever I see a whole page of English in } \\
\text { front of me. }\end{array}$ & 1 & 2 & 3 & 4 & 5 \\
\hline 5 & $\begin{array}{l}\text { I am nervous when I am reading a passage in English when I } \\
\text { am not familiar with the topic. }\end{array}$ & 1 & 2 & 3 & 4 & 5 \\
\hline 6 & $\begin{array}{l}\text { I get upset whenever I encounter unknown grammar when } \\
\text { reading English. }\end{array}$ & 1 & 2 & 3 & 4 & 5 \\
\hline 7 & $\begin{array}{l}\text { When reading English, I get nervous and confused when I } \\
\text { don't understand every word. }\end{array}$ & 1 & 2 & 3 & 4 & 5 \\
\hline 8 & $\begin{array}{l}\text { It bothers me to encounter words I can't pronounce while } \\
\text { reading English. }\end{array}$ & 1 & 2 & 3 & 4 & 5 \\
\hline 9 & $\begin{array}{l}\text { I usually end up translating word by word when I'm reading } \\
\text { English. }\end{array}$ & 1 & 2 & 3 & 4 & 5 \\
\hline 10 & $\begin{array}{l}\text { By the time you get past the funny letters and symbols in } \\
\text { English, it's hard to remember what you're reading about. }\end{array}$ & 1 & 2 & 3 & 4 & 5 \\
\hline 11 & $\begin{array}{l}\text { I am worried about all the new symbols you [I] have to learn } \\
\text { in order to read English. }\end{array}$ & 1 & 2 & 3 & 4 & 5 \\
\hline 12 & I enjoy reading English. & 1 & 2 & 3 & 4 & 5 \\
\hline 13 & I feel confident when I am reading in English. & 1 & 2 & 3 & 4 & 5 \\
\hline 14 & Once you get used to it, reading English is not so difficult. & 1 & 2 & 3 & 4 & 5 \\
\hline 15 & The hardest part of learning English is learning to read. & 1 & 2 & 3 & 4 & 5 \\
\hline 16 & $\begin{array}{l}\text { I would be happy just to learn to speak English rather than } \\
\text { having to learn to read as well. }\end{array}$ & 1 & 2 & 3 & 4 & 5 \\
\hline 17 & $\begin{array}{l}\text { I don't mind reading to myself, but I feel very uncomfortable } \\
\text { when I have to read English aloud. }\end{array}$ & 1 & 2 & 3 & 4 & 5 \\
\hline 18 & $\begin{array}{l}\text { I am satisfied with the level of reading ability in English that I } \\
\text { have achieved so far. }\end{array}$ & 1 & 2 & 3 & 4 & 5 \\
\hline 19 & English culture and ideas seem very foreign to me & 1 & 2 & 3 & 4 & 5 \\
\hline 20 & $\begin{array}{l}\text { You have to know so much about English history and culture } \\
\text { in order to read English. }\end{array}$ & 1 & 2 & 3 & 4 & 5 \\
\hline
\end{tabular}




\section{Appendix B \\ Survey of Reading Strategies \\ (Adapted from Sheorey \& Mokhtari, 2001)}

After reading each statement, circle the number $(1,2,3,4,5)$ which applies to you while you are reading different texts.

' 1 ' means that "I never or almost never do this."

' 2 ' means that "I do this only occasionally."

'3' means that "I sometimes do this."

' 4 ' means that "I usually do this."

'5' means that "I always or almost always do this."

\begin{tabular}{|c|c|c|c|c|c|c|}
\hline Category & Statement & \multicolumn{5}{|c|}{ Never---Always } \\
\hline GLOB1 & I have a purpose in mind when I read. & & 2 & 3 & 4 & 5 \\
\hline SUP1 & I take notes while reading to help me understand what I read. & 1 & 2 & 3 & 4 & 5 \\
\hline GLOB2 & I think about what I know to help me understand what I read. & 1 & 2 & 3 & 4 & 5 \\
\hline GLOB3 & $\begin{array}{l}\text { I take an overall view of the text to see what it is about before } \\
\text { reading it. }\end{array}$ & 1 & 2 & 3 & 4 & 5 \\
\hline SUP2 & $\begin{array}{l}\text { When text becomes difficult, I read aloud to help me understand } \\
\text { what I read. }\end{array}$ & 1 & & 3 & 4 & \\
\hline GLOB4 & $\begin{array}{l}\text { I think about whether the content of the text fits my reading } \\
\text { purpose. }\end{array}$ & 1 & 2 & 3 & 4 & 5 \\
\hline PROB1 & $\begin{array}{l}\text { I read slowly and carefully to make sure I understand what I am } \\
\text { reading. }\end{array}$ & 1 & 2 & 3 & 4 & 5 \\
\hline GLOB5 & $\begin{array}{l}\text { I review the text first by noting its characteristics like length and } \\
\text { organization. }\end{array}$ & 1 & 2 & 3 & 4 & 5 \\
\hline PROB2 & I try to get back on track when I lose concentration. & 1 & 2 & 3 & 4 & 5 \\
\hline SUP3 & $\begin{array}{l}\text { I underline or circle information in the text to help me remember } \\
\text { it. }\end{array}$ & 1 & & 3 & 4 & 5 \\
\hline PROB3 & I adjust my reading speed according to what I am reading. & 1 & 2 & 3 & 4 & 5 \\
\hline GLOB6 & When reading, I decide what to read closely and what to ignore. & 1 & 2 & 3 & 4 & 5 \\
\hline SUP4 & $\begin{array}{l}\text { I use reference materials (e.g. a dictionary) to help me understand } \\
\text { what I read. }\end{array}$ & 1 & & 3 & 4 & 5 \\
\hline PROB4 & $\begin{array}{l}\text { When text becomes difficult, I pay closer attention to what I am } \\
\text { reading. }\end{array}$ & 1 & 2 & 3 & 4 & 5 \\
\hline GLOB7 & $\begin{array}{l}\text { I use tables, figures, and pictures in text to increase my } \\
\text { understanding. }\end{array}$ & 1 & & 3 & 4 & \\
\hline PROB5 & I stop from time to time and think about what I am reading. & 1 & 2 & 3 & 4 & 5 \\
\hline GLOB8 & $\begin{array}{l}\text { I use context clues to help me better understand what I am } \\
\text { reading. }\end{array}$ & 1 & 2 & 3 & 4 & 5 \\
\hline SUP5 & $\begin{array}{l}\text { I paraphrase (restate ideas in my own words) to better understand } \\
\text { what I read. }\end{array}$ & 1 & 2 & 3 & 4 & 5 \\
\hline PROB6 & $\begin{array}{l}\text { I try to picture or visualize information to help remember what I } \\
\text { read. }\end{array}$ & 1 & 2 & 3 & 4 & 5 \\
\hline GLOB9 & $\begin{array}{l}\text { I use typographical features like bold face and italics to identify } \\
\text { key information. }\end{array}$ & 1 & 2 & 3 & 4 & 5 \\
\hline GLOB10 & $\begin{array}{l}\text { I critically analyze and evaluate the information presented in the } \\
\text { text. }\end{array}$ & & 2 & 3 & 4 & \\
\hline
\end{tabular}




\begin{tabular}{l|l|lllll}
\hline Category & \multicolumn{1}{c|}{ Statement } & \multicolumn{4}{c}{ Never---Always } \\
\hline SUP6 & $\begin{array}{l}\text { I go back and forth in the text to find relationships among ideas in } \\
\text { it. }\end{array}$ & 1 & 2 & 3 & 4 & 5 \\
\hline GLOB11 & I check my understanding when I come across new information. & 1 & 2 & 3 & 4 & 5 \\
\hline GLOB12 & I try to guess what the content of the text is about when I read. & 1 & 2 & 3 & 4 & 5 \\
\hline PROB7 & $\begin{array}{l}\text { When text becomes difficult, I re-read it to increase my } \\
\text { understanding. }\end{array}$ & 1 & 2 & 3 & 4 & 5 \\
\hline SUP7 & I ask myself questions I like to have answered in the text. & 1 & 2 & 3 & 4 & 5 \\
\hline GLOB13 & I check to see if my guesses about the text are right or wrong. & 1 & 2 & 3 & 4 & 5 \\
\hline PROB8 & When I read, I guess the meaning of unknown words or phrases. & 1 & 2 & 3 & 4 & 5 \\
\hline SUP8 & When reading, I translate from English into my native language. & 1 & 2 & 3 & 4 & 5 \\
\hline SUP9 & $\begin{array}{l}\text { When reading, I think about information in both English and my } \\
\text { mother tongue. }\end{array}$ & 1 & 2 & 3 & 4 & 5 \\
\hline
\end{tabular}

